\title{
La migración como metáfora de la existencia
}

\section{Migration as a metaphor for existence}

\author{
DOI: https://doi.org/10.29166/tyc.v1i19.2067
}

\section{Sophía Yánez}

Escribe poesía desde los 13 años. Es autora de siete poemarios y está antologada en varias recopilaciones colectivas de poesía nacional e internacional. También sus ensayos han sido recogidos en las Memorias Jalla y la Fundación Antonio Cornejo Polar de Perú. Es candidata a doctora en Literatura Latinoamericana por la Universidad Andina Simón Bolívar-Sede Ecuador. Tiene a su cargo la cátedra de Escritura Creativa en la Facultad de Comunicación Social de la Universidad Central del Ecuador. En 2018 fe seleccionada y antologada por el Austin International Poetry Festival. Ha participado dos veces en TAPFNY en Nueva York y ha sido antologada por dicho festival. En 2019, publica El Sonido de la Pureza con editorial Eskeletra

Correo: sophiasnewplace@hotmail.com

\section{Resumen}

El texto propone comprender el concepto de la migración como el viaje que presupone la existencia. Sostiene que la migración de un estado del ser a otro es un fundamento del aspecto evolutivo y se da por medio del lenguaje. La metáfora, como un vehículo imprescindible para arribar a estados superiores de la conciencia. Con ayuda del pensamiento de María Zambrano y de James Hillman, autores que disertan sobre la metáfora del corazón, y en diálogo con la teoría literaria trazada por Paul Ricoeur en su obra La metáfora viva, la autora ahonda en el concepto de migración. Para finalizar, toma como ejemplo la voz de la poeta norteamericana Joy Harjo, en su obra Conflict resolution for holy beings y hace un viaje al corazón de la palabra de Harjo. En ese viaje, explica cómo la poesía acompaña el ejercicio de migrar de un estado de conciencia a otro en la construcción de una episteme que tiene como centro el fortalecimiento de la propia subjetividad.

Palabras clave: migración, adaptación, cambio climático, metáfora, estrategia, subjetividad.

\begin{abstract}
This text proposes the migration understanding as a trip which presupposes the existence. It sustains the idea that migrating from one state to another is an evolutional aspect and it occurs mainly through the language. Metaphor, as the essential vehicle to arrive to a state of higher states of consciousness. The author pursues the concept of migration with the support of Maria Zambrano's and James Hillman's authors who discourse the "heart metaphor", and also establishes a dialogue with Paul Ricoeurs' literary theory as in his book La metáfora viva. Finally, the author converses with the work of the American poet Joy Harjo, mainly by referring to Conflict resolution for holy beings, and journey to the core of Harjos speech. In this trip, she explains how poetry necessarily accompanies the habit of migrating from one state of consciousness to another, enabling us to build episteme (or knowledge) by means of strengthening our own subjectivity.
\end{abstract}

Keywords: migrations, adaptation, climate change, metaphor, poetry, strategy, subjectivity. 
El corazón es el símbolo y representación máxima de todas las entrañas de la vida, la entraña donde todas encuentran su unidad definitiva, y su nobleza

María Zambrano en Hacia un saber sobre el alma

El universo está compuesto de experiencias que están diseñadas para vencer el aferramiento y el apego hacia el placer, el dolor, el miedo, a todo aquello. $Y$ en tanto exista un lugar donde seas vulnerable, el universo hallará una forma de confrontarte con aquello

\section{Ram Dass (Richard Alpert) en Be Here Now}

Casa adentro, la migración es una metáfora de la existencia. Casa adentro, se gestan los más grandes viajes. George Harrison, el ex beatle, decía en su canción The inner light (La luz interior) que, sin moverse de un lugar a otro, en la quietud, es posible conocerlo todo ${ }^{1}$. ¿Por qué existe, entonces, la migración como un fenómeno sociológico y políticamente relevante a ser analizado? ¿Por qué, en el discurso común pertinente a lo comunicacional, se tiende a pensar que el fenómeno "puro y duro" de la migración, sus datos estadísticos, orígenes y repercusiones se refieren solamente a la migración de masas físicas de gente en una realidad palpable y medible? ¿Dónde empieza y dónde termina la migración? ¿No es acaso la migración, también un fenómeno interior, ligado a la construcción de nuestras subjetividades, de un imaginario y una representación del sí mismo? Y más aún ¿es posible pensar en una existencia vital, sin vernos reflejados a nosotros mismos como seres que migran hacia estados de evolución superior? Parecería ser que la migración es, sobre todo, una metáfora de la existencia humana.

Podemos decir que, en realidad, la existencia humana no puede ser concebida sin entender que, inevitablemente, mientras existimos, migramos de nuestras propias representaciones. Despertamos un día y los antiguos patrones de pensamiento, las formas habituales de ser, los santuarios interiores que erigíamos, de pronto, ya no nos sirven. Lo llamamos "estar en crisis" cuando estamos atrapados en el ciclo de viejas construcciones obsoletas. Despertamos y nos damos cuenta de cómo, para seguir vivos, esos lugares interiores que nos proveían el espejismo de estar vivos o de guarecernos bajo condiciones de vida "seguras", de súbito, ya sólo sirven si nos empujan a desplazarnos hacia otros ribetes del crecimiento y de la vida.

Migramos pues, de conceptos, categorías, paradigmas, prejuicios, relaciones, ideologías, representaciones, signos que una vez fueron parte trascendental de nuestra existencia, como un "plato fuerte" que nos alimentaba, pero que, con la ad-

1 "Without going out of your door,/You can know all things on earth/without looking out of your window,you can know the ways of heaven./The farther one travels/the less one knows/the less one really knows"

"Sin atravesar tu puerta, puedes conocer todas las cosas de este planeta. Sin mirar a través de la ventana, puedes conocer los caminos del cielo. Mientras más lejos viaja uno, menos uno conoce, menos uno realmente conoce” ( traducción mía) 
quisición de nuevas experiencias, con el procesamiento de la vida, con el apremio de adaptarse a las circunstancias y por el cumplimiento de la evolución natural de las especies, ya no nos sirven. Entonces, sin darnos cuenta, debemos migrar hacia nuevas esferas del conocimiento.

Esta idea de la migración, puede compararse con la idea deleuziana del "devenir". Los seres humanos estamos constantemente deviniendo otros. El estar vivos en la plena acepción de lo que es estarlo, nos exige mudar la piel de los conceptos. La idea de lo que es bello o útil o bueno o socialmente aceptable, un día, nos llama a cuestionar y a visitar otras posibilidades para componer la episteme, en otro momento. Todo parecería girar en torno al apremio que tiene la humanidad de dejar de evadir los grandes problemas que ella tiene y cómo sostiene su especie sobre el globo terráqueo. Migramos empujados por el mismo desastre que, como especie, hemos creado: esta suerte de realidad "kraken" que empieza a emerger sin que logremos ocultarla, una realidad que nos exige encarar la más dura y desafiante verdad: la verdad de ser, sin tabúes $^{3}$, quienes en realidad somos: una especie devastadora.

El columnista del New Yorker, Jonathan Franzen, en el artículo What if we stop pretending ${ }^{4}$ fechado 8 de se- tiembre del 2019, habla de la necesidad de dejar de simular que el desorden climático global va a ser controlado. Las implicaciones de este artículo, a nivel de la construcción de la episteme y de representación del mundo, son de mucho impacto. Significaría, tomado literalmente, que ha llegado, con más fuerza que nunca, la hora de migrar a otros niveles de conciencia que nos permitan la adaptabilidad necesaria para ser lo suficientemente sensibles, -a pesar de la desesperanza- para crear estrategias que nos permitan vivir en bienestar individual y colectivo. Dicho en otras palabras, la adaptabilidad para que el espíritu humano pueda, si no desafiar, al menos sostenerse en medio del desastre planetario.

Por lo tanto, en realidad, el fenómeno de las migraciones masivas, debería ser pensado también desde lo que implica primero para la construcción de las subjetividades. Franzen llama a que aceptemos que hemos perdido la partida en relación a la lucha contra el cambio climático. Para él no existe salvación. El fenómeno, irremisiblemente está ocurriendo y la humanidad migra, en condiciones reales, hacia los resultados de dicha catástrofe: sequías, inundaciones, terremotos, mares contaminados, entre otros. Así, el articulista del New Yorker dice, casi en tono de epitafio:

\footnotetext{
Ver Deleuze y Guattari. (200o) Mil Mesetas/ Capitalismo y Esquizofrenia. Pretextos. España.

Ver Watts, Allan. (2011) On the taboo of knowing who you are. Souvenir Press. USA.

¿Y qué pasaría si dejamos de simular? ( traducción mía)
} 
If you're younger than sixty, you have a good chance of witnessing the radical destabilization of life on earth-massive crop failures, apocalyptic fires, imploding economies, epic flooding, hundreds of millions of refugees fleeing regions made uninhabitable by extreme heat or permanent drought. If you're under thirty, you're all but guaranteed to witness it.

Si usted es más joven sesenta, tiene toda la posibilidad de ser testigo de la radical desestabilización de la vida sobre la tierra- daños masivos a las cosechas, fuegos apocalípticos, economías colapsadas, inundaciones épicas, cientos de millones de refugiados fugándose de regiones vueltas inhabitables por el extremo calor o sequía. Si usted está bajo los treinta, está más que garantizado que será un testigo de aquello.

(traducción mía)

Las repercusiones del pensamiento devastadoramente desesperanzado de Franzen son, sin embargo, profundamente humanitarias. Él nos muestra dos alternativas: aceptar el desastre o empezar a pensar qué significa aún el mantener la esperanza en medio del caos. Franzen nos hace recordar la saludable tendencia a no aceptar con demasiada premura y a no volvernos adictos a verdades que, aunque globalmente ciertas, nos dejan de brazos caídos, en una realidad que aún no ha llegado a vestir del todo su proceso dentro de la postmodernidad. Franzen dice "you can accept that disaster is coming, and begin to rethink what it means to have hope".

("Acepta la llegada del desastre y empieza a replantear qué significa tener aún esperanza ) puede ser cierta, pero este "epitafio" de la especie humana pide ser revisado, sobre todo, en lo referente a lo que significa el tener o no tener ya esperanza.

Así como no es saludable el seguir reproduciendo al pie de la letra posturas teóricas hegemónicas, consolidando formas de pensamiento ajenas a nuestra realidad, tampoco es saludable hacer eco de una aceptación masiva y depresiva respecto de que el final del planeta está próximo. Esto es poco más o menos lo que ocurre visiblemente en la academia del tercer mundo, colonizada por la teoría y la tendencia a sobrecitar para refrendar la voz propia. Quizás requerimos migrar hacia formas en donde nuestra voz prevalezca, en esa suerte de "claro de bosque" del que nos hablaba la filóloga española María Zambrano en Claros del Bosque (1986). Hacerlo, también significa identificar y sostener procesos que salvaguarden nuestra subsistencia y permanencia en la arena del debate epistemológico. Posicionarnos en nuestra propia voz, antes de continuar siendo pensados por los procesos que acaecen misteriosamente, sin que nadie sepa exactamente cómo es algo, invariablemente, necesario.

Pensar, entonces. en el vínculo indisoluble entre el tener esperanza y la forma en que devenimos humanos, migrando de nuestra propia desesperanza parece señalar algún norte en la brújula de la conciencia. Solo que las decisiones y movimientos requieren que migremos de lo aleatorio y de lo desorganizado, hacia una dirección específica: aquella que medite acerca de la forma usual en que construimos nuestras propias subjetividades, tarea nada fácil, por cierto, en una sociedad misoneísta y conservadora. Respecto de esto, Allan Watts y Baba Hari Dass, dos de los intelectuales norteamericanos más sonados de la década de los sesentas, señalaban que debemos estar alerta frente a nuestros 
propios procesos mentales. Son nuestras reacciones frente al peligro de ser quienes somos, en nuestro "hridayam" 5 , el mayor peligro al que estamos expuestos. En ese sentido, es posible estar de acuerdo en que una acción climática favorable para el planeta (o dicho de otro modo una acción estratégica que apunta a devolverle a la vida su lugar para soñar) es migrar de la disconformidad y el desencanto que quieren anidar en el corazón humano, hacia acciones que consoliden una organización en medio del caos. La mejor defensa, ante un mundo en desorden, resulta migrar interiormente, para producir soluciones, en una sociedad que amenaza con fagocitar cualquier intento de mantener una subjetividad viva y sensible. Citando nuevamente a Franzen:

any movement toward a more just and civil society can now be considered a meaningful climate action. Securing fair elections is a climate action. Combatting extreme wealth inequality is a climate action. Shutting down the hate machines on social media is a climate action. (...) To survive rising temperatures, every system, whether of the natural world or of the human world, will need to be as strong and healthy as we can make it.$$
---
$$

Cualquier movimiento hacia una sociedad civil más justa puede ahora considerarse una acción climática relevante. Asegurar elecciones limpias es una acción climática. Combatir la inequidad de bienes es una acción climática. Apagar las máquinas del odio en los medios sociales es una acción climática. (...) Para sobrevivir las
}

temperaturas en ascenso, cada sistema sea del orden de la naturaleza o proveniente de la humanidad - necesitará volverse todo lo sano y fuerte que pueda ser.

(traducción mía)

El artículo del columnista del New Yorker que ha recibido fuertes críticas de parte de sus detractores, cierra poniendo en un lugar central la migración hacia un estado de conciencia superior: la necesidad que tiene el ser humano de arraigar en el corazón. Franzen habla de la relevancia de alimentar nuestras existencias con altruismo ${ }^{6}$, paciencia y dedicación a actividades que nos retornen a ser sensibles con la tierra y la naturaleza, como por ejemplo, el sembrar, retornando a la parcela propia, a resolver los predicamentos del diario existir, poniendo atención a las entrañas de la tierra. Esto significa, en lo tangible, hermanarse con la Pachamama, pero también significa, en lo metafísico, un retorno a las condiciones en que germina la palabra, ese lugar en donde acaece, mal que nos pese, nuestra propia subjetividad y capacidad de soñar.

\section{Devenir y migración}

En el libro Mil mesetas, los autores Gilles Deleuze y Félix Guattari, hablan de la idea del "devenir". Dicen que el devenir es el proceso mediante el cual damos y dejamos evidencia, en nuestra profunda capacidad de adaptación, de que estamos vivos. Estamos siempre devi-

5 Se traduce por "el corazón".

6 "Kindness to neighbors and respect for the land-nurturing healthy soil, wisely managing water, caring for pollinators-will be essential in a crisis and in whatever society survives it." Franzen. Op. cit. 
niendo, si es que estamos realmente conscientes de nuestros procesos estéticos, sociales, políticos, de la forma en que nos compartimos. Sin embargo, DeleuzeGuattari trazan un matiz importante respecto de la comprensión del concepto del devenir, porque subrayan que la naturaleza de ésta es algo único e irrepetible de cada ser vivo, porque este proceso no se apoya en la imitación, ni en el seguimiento ciego de algo o alguien, ni en estatuir relaciones formales (convenciones) que resultan vacías7. En cambio, sostienen estos autores que el devenir es un proceso integral, más bien orientado hacia la existencia vital que señalaba Gramsci del intelectual orgánico, el que no sobrecita ni se excita con la justificación de sus ideas basándose en un camino de tordos negros, cardos y espinos teóricos que vuelven espesa e inerte la masa del conocimiento. No. Deleuze y Guattari describen el devenir como sujetos, ontológica y espiritualmente relevantes a través de esta definición:

Devenir es, a partir de las formas que se tiene del sujeto que se es, de los órganos que se posee o de las funciones que se desempeña, extraer partículas, entre las que se instauran relaciones de movimiento y de reposo, de velocidad y de lentitud, las más próximas a lo que se está deviniendo y gracias a las cuales, se deviene. p.275

Bien podríamos decir, entonces, que devenimos seres humanos mientras más agudos y sensibles son nuestros procesos de migración interior respecto de las limitaciones - conceptuales, estéticas, políticas, epistémicas -que nos compo- nen. Pero también, por otra parte, la historia o el registro de cómo migramos dentro de nuestro ser a condiciones superiores mentales, emocionales, espirituales, es el mismo registro sensible de cómo vamos permeando el proceso del deseo $^{8}$, puesto que el deseo es una fuerza motora que impulsa a los seres intuitivamente hacia un proceso de selección natural de qué es y qué no es lo que resulta apremiante de llevar consigo en su proceso de devenir humanos.

lo esencial no es ser o no ser; lo esencial es el proceso que permite pensar que algo llegue a ser, por obra y gracia de las condiciones que promueven la transformación o el metabolismo del devenir. Noser no es la nada; y ser no es lo que permanece idéntico a sí mismo. "Nunca somos los mismos" (...) ni en el cuerpo ni en el pensamiento. Por eso la poesía, en su sentido más amplio, se despliega en medio del vértigo del logos y el flujo incontenible del devenir. (Ramos. op. cit. p18)

A algunos, no obstante, la idea de migrar de las "zonas de confort" o "zonas de comodidad" desde donde se construyen en las relaciones y en los roles que ejecutan, por las funciones condicionadas a las que nos compele la sociedad y la cultura de la que formamos parte, por las exigencias de la académica o del pertenecer a un grupo de intelectuales más o menos letrados, resultan en inseguridad conceptual y emocional y a veces, incluso, en anquilosamiento.

Quizás sería mejor estar alerta y sacudirse de las limitaciones del "deber ser" para abrazar quien uno realmente es.

\footnotetext{
7 “devenir no es imitar a algo o al alguien, no es identificarse con él, tampoco es proporcionar relaciones formales” p.275

8 "el devenir es el proceso del deseo" p.275
} 
Porque la peor humillación que se puede sufrir, no viene de la desaprobación de nuestros semejantes si no del hecho de no podernos asumir como únicos y como seres que tienen el derecho a divergir, a proponer otros caminos, a vislumbrarnos como una criatura puesta en el jardín de la existencia que siente la libertad y el derecho a la completitud. Debemos migrar y devenir hacia ese amor propio de comprendernos como un milagro único e irrepetible, más allá de lo que digan los demás. En ese sentido, Deleuze-Guattari, en la obra a la que me estoy refiriendo, sostienen:

No todo el mundo puede devenir como todo el mundo, convertir ese "todo el mundo" en un devenir. Se necesita mucha ascesis, sobriedad involución creadora: una elegancia inglesa, un tejido inglés, confundirse con las paredes, eliminar lo que resalta demasiado, lo demasiado vistoso. (Deleuze/ Guattari. Op. cit. p.281)

Los seres humanos devenimos quienes somos a lo largo de la existencia. Estamos siempre en profunda alquimia del ser porque eso es lo que pide de nosotros, casa adentro, la existencia. Una de las herramientas que acompaña esta migración interior es, invariablemente, la metáfora como un instrumento fundamental para comprender los procesos del sentir. Sepámoslo o no, nuestro devenir humanos está traspasado por una poética de la existencia.

\section{La metáfora como instrumento fundamental para comprender la migración interna y los procesos del corazón}

La metáfora es un instrumento fundamental para pensar cómo migramos interiormente $^{9 \cdot}$ En los aprendizajes y tensiones que presupone el viaje personal podemos medir nuestros desplazamientos a través del vehículo del sentido que constituye la metáfora. Respecto de ello podemos citar las exploraciones de María Zambrano y de James Hillman en las obras Hacia un Saber del Alma y El Pensamiento del Corazón, respectivamente. Ambos autores convergen en lo que ellos llaman "la metáfora del corazón”. Así, Zambrano, habla de la vida de las metáforas y visita asiduamente los elementos que componen dicha "metáfora del corazón”. Su propósito es resaltar la majestad que éstas ocupan, como herramienta que traza visión y luz inteligible en los procesos interiores del ser humano. En añadidura, la autora española le otorga la función de definir algo que requiere ser "traducido" y que no puede ser expresado de otro modo. Algo así como un excedente al lenguaje utilitario-práctico. La autora se refiere a la función de...

definir una realidad inabarcable por la razón, pero propicia a ser captada de otro modo... la supervivencia de algo anterior al pensamiento, huella en un tiempo sagrado (Zambrano, p.6o)

9 Conviene pensar en la etimología de la palabra "metáfora" que es una palabra proveniente del griego $\mu \varepsilon t a \varphi \rho \rho \alpha$ (metaphora). Metaphora proviene de metapherein formada de meta (fuera o más allá) y depherein (trasladar, ver disforia, fósforo Verónica y teleférico). La metáfora consiste en trasladar el sentido de una palabra o frase a otra. Es, por tanto, un instrumento primordial para comprender los procesos de metamorphosis interior. 
Esa "huella de un tiempo sagrado", que es también "luz que ilumina para salir de imposibles dificultades, luz suave que da consuelo" vive en la metáfora. Lo hace porque el corazón humano restituye su sangre metafísica en las profundas cavidades por donde dicha sangre metafísica circula, porque el corazón sostiene, invariable y valientemente, heridas provenientes de la experiencia y de los avatares de la existencia. Esto queda claro, cuando dice:

el corazón tiene heridas, lentas, a veces de imposible curación; diríase que las heridas en él no se cierran jamás porque tienen un cierto carácter activo, son heridas vivas, como heridas, de las que mana constantemente una gota de sangre que impide su cicatrización, (Zambrano op. cit. p.64)

Pero el ser humano no puede quedarse fijamente y por siempre en el lugar del dolor. La vida exige continuamente cambios en nuestra forma de representarnos la vida, por más que nos pensemos inmutablemente "casados" con ideologías y dogmas, hay un punto en donde éstos se quiebran y tienen que ser reemplazados por la capacidad de vislumbrar la completitud o de ir tras ésta en pos de una más profunda verdad. El Espíritu que nos habita será entonces el motor que impulse a migrar de un "viejo yo" a uno nuevo. Por esto también, la metáfora puede ser pensada en términos de un vehículo del sentido que propulsa un cambio, que posibilita la migración de un estado interior a otro, en donde, si tenemos suerte, habrá una elevación de la conciencia. Por ello, quizás, en la obra La Metáfora Viva, el autor francés Paul Ricoeur, habla de la metáfora como una fuente de cambio, de movimiento o de desplazamiento. (Ricoeur, p. 26)

Ricoeur alerta que el uso de la metáfora ya implica una "migración" respecto del lenguaje común. Dice que es una "desviación" de ese lenguaje, que crea un "lenguaje extraño" por sustitución o préstamo $^{10}$ ( Ricoeur, op. cit. p. 28) En ese "desplazamiento del sentido" que se produce al alejarnos del lenguaje utilitario y práctico de todos los días, subsiste el sentimiento puro de un animal que no se doblega, que se resiste a ser domesticado por los eventos externos, un animal sensible que se desflora a sí mismo y es capaz de ponerse en riesgo para averiguar qué tienen que decir los silencios que le rodean o qué hay más allá del uso casual o vacío que comúnmente tienen las palabras. Este es el constante aprendizaje y tensión que nos vuelve atentos a qué significa o no realmente comunicar y en ello se nos va el ser. Porque en ese otro nivel del sentido, la metáfora posibilita una migración del ser hacia otra esfera del sentido, una menos usual, pero más comprometedora y exigente para quien la escucha o la lee.

Ricoeur dice: "la metáfora es [...] doblemente extraña: porque hace presente una palabra tomada de otro campo, y porque sustituye a una palabra posible, pero ausente". O, dicho de otro modo, "la metáfora nos recuerda que somos animales simbólicos y sensibles, cuya completitud depende de un grado de traslación del sentido hacia algo que está ausente de nuestra existencia y en pos de lo cual nos

10 Para mayor detalle, Ricoeur habla del concepto del "allotrios" que relaciona tres ideas diferentes, pero predominantes en la función de la metáfora, a saberse: la desviación del sentido común, el préstamo de un campo de origen, la sustitución respecto de una palabra ordinaria ausente. Ver obra citada de Ricoeur, p.32 
movemos, para completarnos" (Ricoeur, op. cit. p.31)

Citando a MB Hester en The Meaning of Poetic Metaphor, Ricoeur asigna a la poesía el lugar de lo que se dedica a "figurar, a colorear su lenguaje, a ponerlo en imágenes, en cuadros, a hacer de él una pintura animada y elocuente" ( $\mathrm{Ri}$ coeur, op. cit. p. 88) La metáfora es por eminencia proteica, próxima a la magia de lo que muda de forma ${ }^{12}$. Uno puede reconocer esa cualidad proteica del lenguaje y de la imaginación, por ejemplo, en obras como Macunaima, aquella obra magna de la literatura brasileña, que data de 1928, cuyo autor es Mario de Andrade. En esta obra propia del modernismo brasileño, el lector disfruta de un universo plástico, que muda a cada instante, lúdicamente, reforzando la magia inextinguible de un universo creador y procreador de imágenes. En ese sentido, se puede decir que el lenguaje del mito se hermana con el de la poesía, en cuanto ambos potencian la imaginación y el trastrocamiento de realidades rígidas, suplantándolas por otras más dúctiles, y "espiritualmente relevantes" o si se quiere, que son procesos interiores trascendentes conducidos por el arte de la palabra que busca restituir un sentido perdido o ausente en el universo de la convención, las apariencias fijas y las verdades inmutables.

Ricoeur prosigue enunciando un asunto vital para la comprensión de qué manera las metáforas que generamos son vehículos para la migración ontológica y para esos aprendizajes y tensiones que se generan como fruto de dicha migración. Luego, empodera el concepto de la metáfora, le dota de vida sosteniendo claramente que " el poder de la metáfora consistiría en destruir una categorización anterior para establecer nuevas fronteras lógicas sobre las ruinas de las precedentes” ( p.264) ¿Qué más instrumento podríamos hallar que la metáfora para discutir la continua migración y búsqueda de adaptación frente a la realidad?

De otra parte y dirigiéndonos a la metáfora del corazón, James Hillman en su obra El pensamiento del corazón, cita a Henry Corbin en su estudio sobre Ibn Àrabi restituyendo el lugar del corazón como aquel del conocimiento posible. La capacidad de tener un corazón fuerte y saludable consiste en comprender, dice él, lo que encierra la palabra enthymesis o "acción de meditar, concebir, imaginar, proyectar, desear ardientemente; dicho de otro modo, de tener algo presente en el thymos, que es fuerza vital, alma, corazón, intención, pensamiento, deseo" (Hillman, op cit. p.18) Ambos, enthymesis y thymos, crean la cuerda tensa del aprendizaje humano, en su interacción.

Gastón Bachelard en Poetique de la Reverie, sostiene que la metáfora genera un cambio en nosotros. La imagen poética viste el alma con su propia esencia, que es la de mudar constantemente, desembocando en un cambio cualitativo del ser ${ }^{13}$. El autor francés hace clara la mi-

12 "Metaphor is a device for seeing something in terms of something else..." Paul Henle citando a Kenneth Burke en Metaphor" en Language, Thought and Culture, 1958 (obra citada, a su vez por Ricoeur, op. cit)

13 Podemos relacionar esto con el estado de asombro en donde se produce el cambio de conciencia. Cito: "el poeta le devuelve al lenguaje su irrupción como imagen fulgurante que se enciende y apaga como el destello de una luciérnaga. El poeta no hace ni más, ni menos, que devolver la palabra a su fuente primordial, dejando intacto el milagro, es decir, el asombro del mundo.(Ramos, Francisco José. (2013) en ¿Cómo pensar la poesía? (poema, imagen y escritura) en Escritura e imagen. Vol. 9: 339-357. Universidad de Puerto Rico. p. 11) 
gración del ser de un estado de conciencia a otro a través de la imagen poética, cuando dice: "la imagen poética se convierte en un "principio síquico". Lo que era "un nuevo ser del lenguaje" se convierte en un "incremento de conciencia" o mejor" en un crecimiento del ser" (Ricoeur, op. cit. p.286). Quizás ese incremento de conciencia puede ser comparado al estado de satori del que se habla en el budismo zen, pero también, en un lenguaje más próximo a los movimientos sicologistas integrales, como el expuesto en Las Grandes Metáforas de la Tradición Sagrada ( transformación de la conciencia y la naturaleza humana) de Ralph Metzner, que habla de la capacidad de volcar el alma a un viaje iniciático en donde se produce una profunda modificación interior, es decir, una migración de un nivel de conciencia a una trascendentalmente otra.

Para ello, como lo plantea Karl Graff Dürckheim, sicólogo alemán, hará falta confrontar "la sombra" 14 o impedimento que obstaculiza el paso de un nivel de conciencia a otro. Para una sociedad que tiende a dar oído al materialismo y a un conocimiento tangible, medible y pragmático, la migración de un estado del ser a otro más evolucionado, no siempre guarda un lugar esencial, aun cuando convendría replantearse si en este viaje de la conciencia es sustancialmente el lugar donde los seres humanos deberían empezar a pensarse, si reconocen que la modificación de la conciencia es el primer paso en aportar positivamente a un cambio climático, como lo sosteníamos al inicio de este texto, aludiendo al artículo del columnista Franzen.
Todos tenemos al menos una sombra que impide el ascenso a estados de conciencia superiores. Lo grave es que la(s) desconocemos.

El ejercicio poético, un instrumento para comprender la migración como un proceso interior: Conflict Resolution for Holy Beings de Joy Harjo, un sintomático lugar de partida.

La poesía ocurre en un cuerpo genéticamente dispuesto al aprendizaje, la resolución de conflictos y tensiones y la evolución y superación de los problemas. La naturaleza o Dios fueron sabios en dotarnos con aquello. Culturalmente, no obstante, no siempre los esquemas mentales desde los cuales nos representamos a nosotros mismos y al mundo circundante nos hacen propicios para potenciar la evolución de nuestras formas de pensar. Hoy en día, las sociedades y culturas conservadoras viven la tensión de, por una parte, tener la fortuna de erigir su identidad sobre el pasado. Son ricas en tradiciones, ritos, creencias y prácticas que dan forma al conglomerado de la cultura y, por tanto, de la identidad. No obstante, si no hay resignificación de estas formas, en un presente que nos desafía a hallar otras estrategias discursivas, migrar del malestar ante los desafíos del presente mundo, se vuelve imposible.

El lugar primordial y sagrado que ocupa la labor del poeta, comprendido como un ser de naturaleza mágica y shamánica, puede ser leído como un eslabón crucial en la toma de conciencia y de sobrevivencia del grupo humano al que pertenece. Retomando la idea de Franzen en

14 Ver la obra El héroe y su sombra 
el artículo citado a comienzos de este texto, de que es necesario repensar en qué consiste mantener la esperanza concibiéndose como un ser agente de un cambio climático a nivel planetario, el poeta jugaría un papel crucial en develar cómo se va constituyendo el proceso de la sobrevivencia espiritual. Para explicar más esta idea que enlaza las profundidades de la travesía del lenguaje sígnico de la poesía y el de la sobrevivencia, podemos citar el trabajo de Iuri Lotman, el afamado lingüista de la Escuela de Tartu, en su obra La Semiósfera. Semiótica de la Culturay del Texto, en el que ya se hacía un llamado a la conciencia respecto del lugar crucial que juega el lenguaje en nuestra existencia, si concebimos a la existencia como metáfora de procesos internos migratorios. La actividad poética de un solo ser humano ya es un síntoma que puede proveer información sustancial respecto de la evolución del ser humano y el camino escogido para su evolución o extinción sobre la faz del planeta. Cuando Lotman está hablando de la biosfera, la noosfera y la semiósfera está ya dilucidando que estas tres esferas están irremisiblemente conectadas, como en un cuerpo lo están los distintos órganos. Sobre la biosfera dice:

la biosfera (...) dispuesta sobre la superficie de nuestro planeta y abarcadora de todo el conjunto de la materia viva...) transforma la energía radiante del sol en energía química y física, dirigida a su vez a la transformación de la "conservadora" materia inerte de nuestro planeta. (Lotman p. 22)
Esta biosfera está condicionada, compuesta y atravesada por la actividad sígnica del ser humano que, en tanto primate simbólico, tiene la capacidad de construir una semiósfera. Según Yuri Lotman en La semiósfera (1996): "resultan posibles la realización de los procesos comunicativos y la producción de nueva información"

La escritura poética nos pone, por tanto, frente a un síntoma de cómo migra de sí mismo un ser vivo. El poeta reacciona frente a un mundo externo y produce una compleja serie de respuestas que son traducidas a un lenguaje otro, extraño, fuera del lenguaje utilitario y pragmático, estableciendo fronteras entre su subjetividad y las amenazas que le llegan desde fuera ${ }^{15}$. Tomando estos pensamientos como contexto quisiera aproximarme a la obra poética de Joy Harjo, poeta laureada de los EEUU, en el presente año 2019 y comentar algunas de las líneas que ponen en evidencia un particular estilo de migrar de un estado de conciencia a otro.

En Conflict Resolution for Holy Beings (Resolución de los Conflictos para Seres Sagrados) Joy Harjo ${ }^{16}$ sobrepasa el individualismo norteamericano para arraigar en su más profundo ser. Ganadora de algunos reconocimientos y premios, Harjo supera los tabúes de conocer quien realmente es y se sume en las voces de sus ancestros nativos. Es decir, migra de las líneas superficiales y de las apariencias con las que nos confina la modernidad para construir un ser más hondo, ligado al canto y al cosmos. Este ser busca

15 Los puntos de la frontera de la semiosfera pueden ser equiparados a los receptores sensoriales que traducen los irritantes externos al lenguaje de nuestro sistema nervioso" Lotman, o. cit. p.24

16 Joy Harjo "es una internacionalmente reconocida performer y escritora de la Nación Muscogee Creek y fue nombrada Poeta Laureada de los Estados Unidos en 2019. Es autora de 8 libros de poesía y una memoria, Valentía Insana. Entre sus muchos honores se incluye el Premio a Poesía Jackson, una beca Guggenheim, el Premio William Carlos Williams y el Distinguido Logro en las Artes de los Indios. 
constantemente la respuesta en la conexión con la tierra y la naturaleza.

Aunque es en el capítulo tercero (The Wanderer) ${ }^{17}$ donde encontramos con mayor fuerza el tema del desplazamiento interior, el libro, en su totalidad, ya representa un viaje hacia el terreno del conocimiento sagrado y se contrapone al ruido del mundo externo. Así, en uno de los poemas de apertura, Once the World was Perfect ${ }^{18}$, Harjo comparte en sus versos el milagro de su canto migratorio. Se arraiga en un pasado perfecto y armónico, en donde los seres vivían en completitud y perfección y va dando espacio al ingreso de los elementos que riñen con ese espíritu de armonía.

Once the world was perfect, and we were happy in that world.

We took it for granted.

Discontent began a small rumble in the earthly mind.

Then Doubt pushed through with its spiked head.

And once Doubt ruptures the web,

All manner of demon thoughts

Jumped through- We destroyed the world we had been given

For inspiration, for life...

(Harjo, op. cit. p14)

Una vez el mundo fue perfecto y éramos felices en aquel mundo./ Luego lo tomamos por sentado/ El descontento empezó un rumor pequeño en la terrena mente./ Entonces, la Duda atravesó con su cabeza de púa,/ y una vez que la Duda rom- pió la red,/ toda clase de pensamientos demónicos/ saltaron también-/ Nosotros destruimos el mundo que nos había sido dado/ para inspiración y vida nuestra.

(traducción mía)

En este fragmento queda clara la disrupción de un universo otrora idílico. Este mundo, descrito con la imagen de una red perforada y la perfección interrumpida, es culpa de los "pensamientos demónicos" provenientes de una "mente mundana”. Adviene, entonces, la pandemia de maldiciones en el corazón humano que convergen a forjar un estado de oscuridad compartido y azuzado, según el poema de Harjo, con "la envidia, el miedo, la codicia y el odio". El poema prosigue describiendo los tropezones y choques de los seres que habitaron la oscuridad. También adviene la ignorancia respecto de cómo continuar la convivencia. El poema de Harjo, arraigado en la sabiduría nativa de la Nación Muscogee Creek, cierra circularmente, proveyendo suelo al espíritu de la errancia humana. Alguien encuentra una frazada y aprendió a compartirla. Este acto de bondad, devuelve la luz al universo.

A spark of kindness made a light.

The light made an opening in the darkness.

Everyone worked together to make a ladder. ${ }^{19}$

Harjo reitera una verdad universal, a la que todos, como migrantes de nuestro propio ser y como agentes del

17 El término "wanderer" se traduce por "espíritu errante o andariego" y nos remite a la idea del desplazamiento del ser de una esfera del conocimiento a otra, en un viaje interior.

18 "Una vez el mundo era perfecto" ( Traducción mía)

19 "Una chispa de bondad trajo la Luz./La luz hizo una apertura en la oscuridad/ Todos trabajaron juntos para construir una escalera" (traducción mía) 
"cambio climático" a mayor escala, requeriríamos volver: la presencia del gesto del amor que provee sentido a la oscuridad. Pero Harjo, como también lo planteaban los mazdeístas ${ }^{20}$, parecería recordarnos que el alma humana precisa mantenerse en estado de gratitud frente a lo adverso, pues la adversidad es la promesa de que, migrando de ese estado de involución, podemos arribar a una orilla de luz, próspera no solo para uno, individualmente, si no para el género humano. Así, en el poema de Harjo, a través de la escalera una persona, cruza al "siguiente mundo" (migra) y luego se produce una suerte de salvación, en un tiempo mítico, hasta arribar al instante del presente. Finalmente, el poema de Joy Harjo termina en que una persona del Clan del Viento logra "limpiar el camino" para las generaciones futuras... hasta llegar a una nueva luz de la mañana, líneas que tal vez la poeta quiso proyectar, en un túnel de tiempo, a un futuro interlocutor de su estirpe espiritual genética.

A Wind Clan person climbed out first into the next world.

And then the other clans, the children of those clans, their children

And their children, all the way through time-

To now, into this morning light to you (Harjo p.15)

Una persona del Clan del Viento trepó primero al siguiente mundo.

Luego fueron los otros clanes, los hijos de aquellos clanes, sus hijos

y sus hijos, todo el trayecto a través del

\author{
tiempo - \\ hasta el ahora, en esta luz de la mañana que \\ llega a ti
}

(traducción mía)

La persistencia de la luz es la persistencia del corazón humano en la traducción que hace la poeta Harjo de los fundamentos de vida con los que nativos de la nación Muscogee Creek, de la cual es parte, han construido su realidad. Una nación que los puso, si con suerte, en reservas, despojándolos de sus tierras y reduciendo sus medios para vivir en contacto con la naturaleza. Se podría bien hablar de otros grupos nativos en Estados Unidos: los Dakota, los Sioux, los Ojibwa, ingresar a todo un capítulo acerca de cómo las voces nativas han sido acalladas por los procesos civilizatorios, a nivel mundial... Solo cabe reconocer, en este caso específico, la profunda paradoja y contradicción que resulta evidente y sintomática, en la articulación del éxito que presupone la existencia mundana, el que Harjo esté nombrada poeta del año 2019, en los EEUU, mientras sigue creciendo el "Dakota pipeline" (oleoducto de Dakota) que atraviesa varios estados de Norteamerica ${ }^{21}$; un sinsentido.

Mientras tanto, en la voz poética de Harjo se juega el pellejo la humanidad entera. Por esto, conviene prestar especial atención al anteriormente mencionado capítulo tercero en Conflict Resolution for Holy Beings, The Wanderer. Justamente en este tramo del texto, es posible percibir cómo Harjo nos llama a migrar de nuestra

20 Se sabe que en el mazdeísmo / zoroastrismo, como en muchas otras religiones, la lucha entre las fuerzas del bien y del mal se acogen a la batalla entre la luz y la oscuridad.

21 Ver https://americanindian.si.edu/nk36o/plains-treaties/dapl sobre la irrupción del Tratado de Laramie y la violencia contra los pueblos Sioux y Dakota en EEUU. 
condición de seres modernos, apesadumbrados con la lógica de Occidente, para retornar a un mundo donde predomina la sabiduría de los ancestros nativos de la tierra. El llamado es el retorno a las creencias sencillas que nos vinculan a la naturaleza. En ese sentido, en poemas como "Talking with the Sun", "Going Home" "One day there will be horses" la poeta reitera una profunda herida que solo sana en la esperanza de cobijarse en la sabiduría cíclica de la naturaleza y la posibilidad de "retornar a casa" para hallar las raíces ancestrales que le permiten cantar su nombre al viento.

Quizás, en ese sentido, el poema "Talking with the Sun" nos sirve de ejemplo, para comprender el proceso de migración al que nos llama Harjo. En el cuerpo de este poema es posible sentir las fuerzas antagónicas que componen su subjetividad y que la ponen al borde casi de la imposiblidad de ser quien es. Sin embargo, la poeta resuelve el malestar espiritual que le aqueja como producto de ser una criatura sumergida en las contradicciones del modo de vida occidental. $\mathrm{Su}$ creencia en el Poder del Sol (signo inequívoco de la Nación Muscowagee Creek) está presente:

I believe in the sun.

In the tangle of human failures of fear, greed, and

Forgetfulness, the sun gives me clarity.

When explorers first encountered my people, they called us

Heathens, sun worshippers.

They didn't understand that the sun is a relative, and

Illuminates our path on this earth.

(Harjo.op. cit. p.31)
Creo en el sol.

En el enredo de las fallas humanas del miedo, codicia y el olvido,

El sol me provee de claridad.

Cuando los exploradores primero encontraron a mi gente,

Nos llamaron paganos, veneradores del sol. Ellos no comprendieron que el sol es un pariente, $\mathrm{y}$

Que ilumina nuestro sendero sobre esta tierra.

(traducción mía)

Algo tan simple como el gesto de saludar al sol recuerda el camino que el corazón asume en su proceso de purificación respecto de lo mundano y subraya la relación sagrada que el ser humano necesita tener para enarbolar, en el cuerpo de sus palabras, un cosmos que cante y sostenga su existencia sobre la faz de la tierra. Aquí también se juega el valor no ponderado por Occidente en monedas, de que exista la intimidad posible entre el alma del ser humano y la naturaleza. Esta intimidad, (de la que también habla Tony Hoagland y Kay Cosgrove en The Art of Vice, Poetic Principles and Practice y a la que el crítico y poeta ecuatoriano Iván Carvajal, en su obra de ensayos críticos Trasiegos, mencionan como centrales para la construcción de una episteme poética) es una experiencia fisiológica única en donde, tanto el repertorio de los procesos neurolinguísticos como la respiración y tono muscular de las palabras, se vuelven síntomas de la profunda capacidad que tiene el ser humano de estirar su ADN hacia los límites más inimaginables. El autor Ramos, en su ensayo ¿Cómo pensar la poesía? (poema, imagen y escritura $^{22}$ invita a que repensemos los alcances de la metáfora, repotenciando su

22 Ver Ramos, Francisco José. Escritura e imagen. Vol. 9: 339-357. Universidad de Puerto Rico 
valor a una experiencia fisiológica, cuando dice:

La metáfora no es solamente una figura retórica. La metafora es, de una parte, "una profunda experiencia fisiológica", como alguna vez dijera Cioran; $y$, de otra, es un efecto de superficie, esto es: la inscripción más evidente por la que el lenguaje sale a la luz. Y visto aun desde otra perspectiva, la metáfora es lo que nos permite lidiar con el sentido de los límites y el abismo de lo ilimitado. (Ramos p.14)

La metáfora sobre la cual Harjo construye su poética es un fenómeno fisiológico que vibra con el misterio de evolucionar hacia otras esferas del ser para que el milagro de existir persista aun cuando sea intraducible en valores de cambio. Son lecciones de abismo que, sin embargo, la poeta Harjo asume atravesando con su lenguaje el epítome del capitalismo moderno: el mismísimo Times Square. Y lo hace subrayando el nacimiento de su nieta bajo un nuevo sol. Este desplazamiento genera en ella y en quien la sigue, el lector, la tracción de dos fuerzas antagónicas que, en su tensión, nos hacen migrar de una confrontación entre aquellas dos fuerzas antagónicas, hacia un nuevo amanecer. La belleza de la vida que se abre paso, entre el cemento y los signos de las multinacionales es evidente en este fragmento en donde se destaca el sabio dramatismo de sus palabras:

I walked out of a hotel room just off Times Square at dawn

To find the sun.

It was the fourth morning since the birth of my fourth

Granddaughter.

This was the morning I was to present her to the sun, as a/

Relative, as one of us. It was still dark, overcast as I walked
Through Times Square.

I stood beneath a twenty-first century totem pole of symbols

Of multinational corporations, made of flash and neon.

I carried this newborn girl within the cradleboard of my heart.

I held her up and presented her to the sun, so she would be

Recognized as a relative,

So that she won't forget this connection, this promise,

So that we all remember, the sacredness of life (Harjo, op. cit. p.31)

Salí del cuarto del hotel, cerca del Times Square, a la madrugada,

Para hallar el sol.

Era la cuarta mañana desde el nacimiento de mi cuarta nieta.

Esta fue la mañana en que yo debía presentarla ante el sol,

Como una pariente, como uno de nosotros. Aún estaba oscuro,

Nublado, mientras caminaba atravesando el times Square.

Me paré bajo un poste del siglo veintiuno con símbolos

De corporaciones multinacionales, hechas de destellos y luces de neón.

Cargué esta niña recién nacida, en la cuna de mi corazón.

La alcé y la presenté al sol,

Para que pudiera ser reconocida como una pariente,

Para que no olvidara este vínculo, esta promesa,

Para que todos podamos recordar, el rostro sagrado de la vida

(traducción mía)

Pero esta promesa sagrada de la vida que se alza, dentro del Times Square, 
al que los occidentales llaman "centro del universo", nos recuerda que, mientras no haya un retorno sentido y sincero al gesto íntimo de una escucha aguda y desvergonzada, que tome en cuenta la resistencia y la sabiduría de los pueblos ancestrales, no hay posibilidades de que la civilización se salve, tal y como la conocemos, pues el sacrificio de las verdades más profundas, espiritualmente hablando, nos condenan de antemano a la orfandad y a la intemperie.

Por otra parte, en el poema más extenso del libro de Harjo, que es el que le da título a la obra, se destaca el elemento tierra que cobra vitalidad temática. Harjo llama a que migremos de la ignorancia tecnológica, del ruido de la vida moderna, de su sinsentido a comprender que existe un vínculo sagrado con la naturaleza. $Y$ más allá de eso, dice que somos el lenguaje de la naturaleza y que el registro de tal relación está inscrita en el alma de los seres vivientes que nos acompañan en nuestra aventura de vida.

Recognize whose lands these are on which we stand.

Ask the deer, turtle, and the crane.

Make sure the spirits of these lands are respected and

Treated with goodwill.

The land is being who remembers everything.

You will have to answer to your children, and their children,

And theirs -

(Harjo p.77)

Reconozcan a quiénes pertenece esta tierra sobre la cual nos erguimos.

Pregunten al venado, a la tortuga a la grulla.

Asegúrense que los espíritus de estas tierras sean respetados

Y tratados con buena voluntad.
Esta tierra es un ser que lo recuerda todo. Tendrán que responder por ella ante sus hijos, y sus hijos

Y los que siguen

(traducción mía)

En el fragmento anterior es posible hallar similitudes (y no pocas) con el sentir de los pueblos nativos y ancestrales de los Andes. Harjo trabaja la herida del abandono y la orfandad espiritual para restituir la importancia de desplazar el eje del sentido de la razón a la esfera del corazón. En el poema "One day there will be horses" (Un día habrá caballos), la poeta canta a la esperanza de un día mejor en donde exista la abundancia del Espíritu en condiciones que permitan un "retorno a casa". No se refiere, empero, a un regreso físico a un espacio concreto y tangible, sino más bien a las coordenadas en que el alma encuentra cobijo y solaz en hallar la valentía suficiente para saber que su posibilidad de evolucionar es el mismo retorno a las raíces y valores de las que un día renegó. Así, Harjo canta:

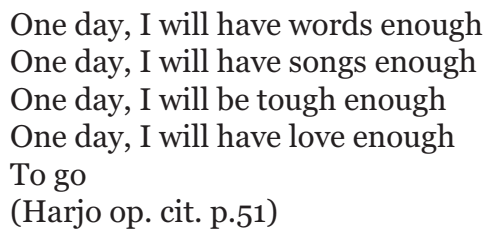

One day, I will have words enough

One day, I will have songs enough

One day, I will be tough enough

One day, I will have love enough

To go

(Harjo op. cit. p.51)

Un día tendré las palabras suficientes Un día, tendré las canciones suficientes Un día, seré lo suficientemente fuerte. Un día tendré el amor suficiente Para volver a casa

(traducción mía)

Esta idea de que solo es posible migrar retornando a casa, se reitera también en el poema "Going Home" (Volviendo a 
casa) donde la voz poética persiste en evocar las condiciones necesarias para el retorno a un lugar espiritualmente sano en donde la existencia halla finalmente un cobijo y un sentido de pertenencia. Nuevamente, es la invitación al gesto sencillo del corazón y el ingreso a un tiempo paciente, de espera, lo que ayuda en el proceso de migración hacia un estado de conciencia más alto:

Let's just sit down here under the stars Wrapped in my shawl, and figure out How to get our homelands back Going home going home going home... (Harjo. Op. cit. p. 53)

Sentémonos aquí no más bajo las estrellas Envuelta en mi chalina y pensemos Cómo hacer nuestras a nuestras tierras Volver a casa, volver a casa, volver a casa...

(traducción mía)

Toda esta reflexión hace recordar uno de los poemas más bellos del poeta chileno Fabio Morabito, quien en su texto No tener casa, nos provee de una llave que cabe a la perfección en el cerrojo de la migración, como metáfora de la existencia. Morabito recuerda el axioma central de la vida, que es el devenir de lo humano en humano, con la imagen de una casa proteica, sin muros, sin bordes, en eterna transformación. Tal como la describe a esta casa, la imagen poética ratifica su soberanía frente a la realidad. Se convierte en la herramienta fundamental para ahondar en la conciencia, ser escritura es ser el fluir de lo que migra, desde las capas más profundas del mar del que nos desprendemos.

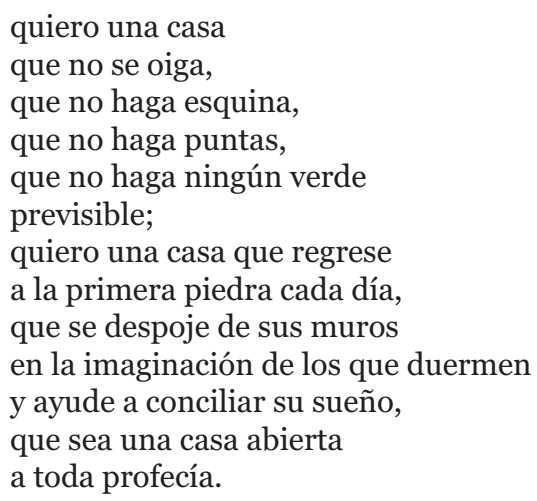

(Fabio Morabito)

Casa adentro resolvemos las paradojas e imposibilidades sobre las que crece nuestro ser. Casa adentro resolvemos los conflictos y malinterpretaciones fundamentales de ser quienes somos. Si nos hemos de asumir esperanzadamente como agentes de un cambio climático, es hacia adentro donde debemos trabajar. Los trabajos de vida de pensadores que afectaron el modo de pensar de la década de los sesenta en Estados Unidos, como Allan Watts, Ram Dass,Timothy Leary, Ralph Metzner, sumados a la oleada del movimiento beatnik, aún están llamando a que migremos de las limitaciones con los que la realidad nos oprime y aliena.

Pensarnos como seres que aportan al cambio climático es un proceso que empieza casa adentro. Tener esperanza en que podamos ser agentes del cambio climático, quizás significa primero que uno debe migrar de sí mismo para continuar siendo quien es. Entonces, será posible que la poética de la vida germine en procesos hondos para todos. 


\section{Bibliografía}

Barrios, A. Alpert, Richard (Ram Dass) (1971). Be Here Now. Lama Foundation, San Cristobal, New Mexico.

Bachelard, Gaston. (2000) La intuición del Instante. Fondo de Cultura Económica, Méjico.

Deleuze, Gilles/ Guattari, Félix. (2000) Mil Mesetas/ Capitalismo y Esquizofrenia. Pretextos. España.

Harjo, Joy. (2015) Conflict resolution for Holy Beings. Norton and Company. New York

Hillman, James. (2001) El pensamiento del corazón. Siruela. Madrid.

Hoagland, Tony. (2019) The Art of Voice. Poetic Principles and Practice. Norton and Company. New York.

Kafka, Franz. (2012) Obras Selectas. Edimat Libros, Madrid.

Kafka, Franz. (2003) El libro del hambre. Siripus. Barcelona.

Lotman, luri. (1996) La semiósfera. Semiótica de la Cultura y del Texto. Ediciones Cátedra, Madrid.

Malatesta, Julián (2007) La imagen poética. Escuela de Estudios Literarios. Universidad del Valle. Colombia

Metzner, Ralph. (1987) Las grandes metáforas de la tradición sagrada. La transformación de la conciencia y la naturaleza humana. Editorial Kairós. Barcelona.

Ramos, Francisco José. (2013) PDF. "¿Cómo pensar la poesía? (poema, imagen y escritura)", en Escritura e imagen. Vol. 9: 339-357. Universidad de Puerto Rico.

Reverdy, Paul. "La Imagen Poética". Revista El Golem. Tomado de Nueva Era. Año 1. No.4

Ricoeur, Paul. (2001) La Metáfora Viva. Ediciones Cristiandad. Madrid

Watts. Alan. (2011) On the taboo of knowing who you are. Souvenir Press. USA.

Yánez, Sophía. (2016) Puerto de Hayu Marka. Hojas y Signos, Quito.

Zambrano, María. (2002) Hacia un saber sobre el alma. Alianza Editorial. Madrid.

-(2007) Algunos lugares de la poesía. Editorial Trotta. Madrid. 